\title{
EFICÁCIA DA MISTURA EM TANQUE GLYPHOSATE + CARFENTRAZONE-ETHYL NA DESSECAÇÃO DE PLANTAS DANINHAS
}

\author{
Antônio Carlos de Barros ${ }^{1}$
}

'Eng ${ }^{\circ}$. Agr ${ }^{\circ}$., Pesquisador. Agência Goiana de Desenvolvimento Rural e Fundiário. Rua Marechal Rondon, s/n. Jataí, GO 75800-069

\begin{abstract}
RESUMO
Foi conduzido um ensaio no município de Chapadão do Céu, GO, objetivando avaliar a eficácia biológica da mistura em tanque de glyphosate+carfentrazone-ethyl, comparando-a com glyphosate $+2,4-\mathrm{D}$ na dessecação de plantas daninhas para o plantio direto da soja. O delineamento experimental adotado foi o de blocos ao acaso, com quatro repetições e nove tratamentos, relacionados a seguir: glyphosate $(720$ e $1080 \mathrm{~g} / \mathrm{ha})$, glyphosate+2,4-D $(720+670 \mathrm{e} 1080+402 \mathrm{~g} / \mathrm{ha})$, glyphosate+carfentrazone-ethyl $(360+30,720+25$ e $1080+20 \mathrm{~g} / \mathrm{ha}), 2,4-\mathrm{D}(670 \mathrm{~g} / \mathrm{ha})$ e testemunha. A cobertura vegetal da área no momento da aplicação dos produtos era de 95\%, com maior frequência para o capim-colchão (Digitaria horizontalis), picão-preto (Bidens pilosa), guanxuma-preta (Sida rhombifolia), guanxuma-branca (Sida cordifolia) e em menor número a erva-quente (Spermacoce latifolia). As avaliações de controle foram efetuadas aos 8, 18 e 28 dias após tratamentos, adotando-se a escala percentual de zero a cem por cento de controle. A combinação de glyphosate+carfentrazone-ethyl (720+25 e $1080+20 \mathrm{~g} / \mathrm{ha}$ ) propiciou eficiente controle do capim-colchão, picão-preto, guanxuma-branca, guanxuma-preta e erva-quente. A mistura glyphosate+2,4-D (720+670 e 1080+402 g/ha), obteve eficiente controle das plantas daninhas, com exceção da erva-quente, que foi satisfatoriamente controlada. Glyphosate $(720 \mathrm{e} 1080 \mathrm{~g} / \mathrm{ha})$ foi eficaz no controle das plantas daninhas, exceto para erva-quente, cujo controle foi deficiente. O herbicida 2,4-D (670 g/ha), proporcionou baixo controle do capimcolchão, controle satisfatório da erva-quente e eficiente controle das demais espécies infestantes. Conclui-se ser possível a substituição da mistura glyphosate + 2,4-D (720+670 e 1080+402 g/ha) por glyphosate + carfentrazone-ethyl (720+25 e $1080+20 \mathrm{~g} / \mathrm{ha}$ ), na dessecação de plantas daninhas, para implantação de culturas no sistema de plantio direto.
\end{abstract}

Palavras-chave: herbicidas, 2,4-D, carfentrazone, glyphosate, plantio direto.

\section{ABSTRACT \\ Evaluation of the efficacy of glyphosate+carfentrazone-ethyl on desiccation of weeds in soybean}

A test was conducted in Chapadão do Céu city, state of Goiás, to evaluate the biological efficacy of a tank mixture of glyphosate + carfentrazone-ethyl, comparing it with glyphosate $+2,4-\mathrm{D}$ on the desiccation of weeds in a soybean plantation. The experimental design adopted was that of random blocks, with four replications and nine treatments, as follows: glyphosate $(720$ and $1080 \mathrm{~g} / \mathrm{ha})$, glyphosate $+2,4-\mathrm{D}(720+670$ and $1080+402 \mathrm{~g} / \mathrm{ha})$, glyphosate + carfentrazone-ethyl $(360+30,720+$ 
25 and $1080+20 \mathrm{~g} / \mathrm{ha})$, and 2,4-D (670 g/ha), as well as a control treatment. The vegetative cover of the area at application was $95 \%$, with a higher frequency of capim-colchão (Digitaria horizontalis), picão-preto (Bidens pilosa), guanxuma-preta (Sida rhombifolia), guanxuma-branca (Sida cardifolia) and, in lower numbers, erva-quente (Spermacoce latifolia). The evaluations were carried out at 8,18 and 28 days after treatment, adopting a percentual scale in which zero meant no control and one hundred corresponded to total control. The combination of glyphosate + carfentrazone-ethyl $(720+25$ and $1080+20$ g/ha $)$ caused efficient control of D. horizontalis, B. pilosa, S. cordifolia, S. rhombifolia and Spermacoce latifolia. Glyphosate $+2,4-\mathrm{D}(720+670$ and $1080+402 \mathrm{~g} / \mathrm{ha}$ ), caused efficient control of weeds, except Spermacoce latifolia, which was satisfactorily controlled. Glyphosate (720 and $1080 \mathrm{~g} / \mathrm{ha}$ ) was efficient for weed control, except Spermacoce latifolia, whose control was deficient. The hercicide 2,4D (670 g/ha), caused low level control of D. horizontalis, satisfactory control of Spermacoce latifolia and efficient control of the other species. A substitution of the herbicide 2,4-D by carfentrazone-ethyl in combination with glyphosate is possible for the desiccation of weeds in no till plantations.

Key-words: herbicides, 2,4-D, direct plantation.

\section{INTRODUÇÃO}

Tem sido observado, na região Central do Brasil, aumento considerável da área com cultivo mínimo e/ou plantio direto. No entanto, nesta região, em consequência da dificuldade de cultivo durante a entre-safra, em função, principalmente, do déficit hídrico, são poucas as alternativas de culturas que apresentam potencial para a produção e/ou formação de cobertura morta, visando o plantio direto das culturas de verão (Pereira, 1998).

A formação da palhada sobre o solo, para semeadura de espécies em sistema de plantio direto, tem sido assegurada, principalmente, a partir da cobertura vegetal de uma área em pousio composta por plantas daninhas, além dos restos culturais da safra anterior. Desse modo, espécies como a trapoeraba (Commelina benghalensis), a guanxuma (Sida rhombifolia), a erva-quente (Spermacoce latifolia), entre outras, têm sido selecionadas ao longo dos anos, pelos herbicidas utilizados na dessecação das plantas daninhas em pré-semeadura da cultura.

O herbicida 2,4-D, de modo geral, tem sido utilizado na dessecação (manejo) das plantas daninhas dicotiledôneas, em aplicação isolada ou em combinações com glyphosate ou sulfosate. No entanto, este herbicida poderá causar danos nas culturas susceptíveis nas proximidades da área tratada, além do agricultor necessitar de um período de 10 (dez dias) após a aplicação do 2,4-D, para efetuar a semeadura da soja na área (EMBRAPA, 1997).

Ao adotar a sucessão de culturas (safrinha) deve ser feita a implantação da primeira cultura no início da estação chuvosa. Quando da utilização do 2,4-D para o manejo das plantas daninhas torna-se obrigatória a espera de dez dias até a semeadura. Em algumas situações este período pode dificultar a adoção deste sistema.

A fỉm de substituir o herbicida 2,4-D na dessecação, algumas alternativas têm sido adotadas pelos agricultores, onde a mistura em tanque de flumioxazin com glyphosate tem apresentado resultados animadores, conforme atestam Melhorança \& Júnior (1998), Pereira \& Fukushima (1998) e
Ferreira et al. ( 1998).

Atualmente, está sendo desenvolvido no Brasil um novo herbicida, o carfentrazone-ethyl que, uma vez absorvido pelas folhas, inibe a formação da enzima protoporfirinogênio oxidase (PPO), que participa na síntese da clorofila. Na presença de luz ocorre a ruptura das membranas celulares, causando necrose dos tecidos foliares e a morte da planta (FMC, s.d). Carfentrazone-ethyl pode ser utilizado em combinação com glyphosate ou sulfosate, podendo aumentar a fitotoxicidade dos mesmos, o que poderá tornar-se uma alternativa promissora. Esta prática poderá permitir redução da dose utilizada do glyphosate. mantendo um nível de controle eficiente da vegetação daninha, além de não proporcionar resíduos no solo, permitindo o plantio das culturas imediatamente após a aplicação dos herbicidas (FMC. s.d.).

O objetivo desta pesquisa foi avaliar a eficácia da mistura em tanque de carfentrazone-ethyl com glyphosate, comparando-a com o 2,4-D+glyphosate, para o controle (dessecação) das plantas daninhas.

\section{MATERIAL E MÉTODOS}

Foi conduzido um experimento na Fazenda Perdizes, município de Chapadão do Céu, GO, com o solo classificado como Latossolo Vermelho-Amarelo, distrófico, de textura arenosa, contendo $18 \%$ de argila e 2,2\% de matéria orgânica.

O delineamento experimental adotado foi de blocos ao acaso, com quatro repetições e nove tratamentos a seguir relacionados: glyphosate (720 e $1080 \mathrm{~g} / \mathrm{ha})$, glyphosate+2,4D $(720+670$ e $1080+402 \mathrm{~g} / \mathrm{ha})$, glyphosate+carfentrazoneethyl $(360+30,720+25$ e $1080+20 \mathrm{~g} / \mathrm{ha}), 2,4-\mathrm{D}(670 \mathrm{~g} / \mathrm{ha}) \mathrm{e}$ uma testemunha sem controle. As parcelas experimentais mediram $7 \mathrm{~m} \times 3 \mathrm{~m}=21 \mathrm{~m}^{2}$, com a área útil de $5 \mathrm{~m} \times 2 \mathrm{~m}=10$ $\mathrm{m}^{2}$.

Os herbicidas foram aplicados em 11/11/99, com a 
cobertura do solo em torno de $95 \%$. As plantas daninhas monocotiledôneas mediam de 15 a $35 \mathrm{~cm}$ de altura e as dicotiledôneas apresentavam de 8 a $80 \mathrm{~cm}$ de altura. No momento da aplicação dos produtos, que se deu das 9:20 ás 9:50 h, a temperatura do ar foi de $27^{\circ} \mathrm{C}$ e a umidade relativa do ar $63 \%$. As precipitações diárias no Chapadão do Céu-GO, no período de outubro/1999 à janeiro/2000 estão registradas na Tabela 1.

Para a aplicação dos herbicidas foi utilizado um pulverizador costal, pressurizado a $\mathrm{CO} 2$, pontas de pulverização (bicos) tipo leque, série TT 110.02, calibrados para 3,0 $\mathrm{kg} / \mathrm{cm}^{2}$ de pressão, consumindo $200 \mathrm{l}$ / ha de calda.

O grau de controle das plantas daninhas foi obtido através de avaliações visuais, realizadas aos 8,18 e 28 dias após a aplicação dos tratamentos (DAT), utilizando a escala percentual, em que zero correspondeu a nenhum controle e cem a controle total das plantas daninha avaliadas.

Tabela 1. Precipitações diárias (em mm), no período de outubro/1999 a janeiro/2000. Chapadão do Céu, $\mathrm{GO}$.

\begin{tabular}{|c|c|c|c|c|}
\hline \multirow{2}{*}{ Dias } & \multicolumn{3}{|c|}{1999} & \multirow{2}{*}{$\begin{array}{c}2000 \\
\text { Jan }\end{array}$} \\
\hline & Out & Nov & Dez & \\
\hline 1 & 0,0 & 0,0 & 0,0 & 0,0 \\
\hline 2 & 0,0 & 0,0 & 0,0 & 28,8 \\
\hline 3 & 0,0 & 0,3 & 18,6 & 83,0 \\
\hline 4 & 0,0 & 45,0 & 0,0 & 65,6 \\
\hline 5 & 0,0 & 7,4 & 0,1 & 0,0 \\
\hline 6 & 31,0 & 0,0 & 0,3 & 5,4 \\
\hline 7 & 0,0 & 0,0 & 0,0 & 3,1 \\
\hline 8 & 1,4 & 0,0 & 14,9 & 1,5 \\
\hline 9 & 0,0 & 0,4 & 12,5 & 0,0 \\
\hline 10 & 0,0 & 1,2 & 64,3 & 0,0 \\
\hline 11 & 0,0 & 0,0 & 1,4 & 0,0 \\
\hline 12 & 0,0 & 0,0 & 23,1 & 0,0 \\
\hline 13 & 0,0 & 32,5 & 0,5 & 4,8 \\
\hline 14 & 11,8 & 15,3 & 0,0 & 0,0 \\
\hline 15 & 0,0 & 0,0 & 3,4 & 0,0 \\
\hline 16 & 0,0 & 0,0 & 0,0 & 0,0 \\
\hline 17 & 0,0 & 0,0 & 0,0 & 0,0 \\
\hline 18 & 1,6 & 0,0 & 0,0 & 0,4 \\
\hline 19 & 3,0 & 0,0 & 0,0 & 0,0 \\
\hline 20 & 0,0 & 0,0 & 0,0 & 4,2 \\
\hline 21 & 0,0 & 41,9 & 0,0 & 26,0 \\
\hline 22 & 0,0 & 0,0 & 1,1 & 0,2 \\
\hline 23 & 0,0 & 6,4 & 0,0 & 1,6 \\
\hline 24 & 0,0 & 3,2 & 1,1 & 0,0 \\
\hline 25 & 4,1 & 3,2 & 0,0 & 4,2 \\
\hline 26 & 0,0 & 8,8 & 13,0 & 22,0 \\
\hline 27 & 47,2 & 16,7 & 0,0 & 21,0 \\
\hline 28 & 1,3 & 1,2 & 35,4 & 1,6 \\
\hline 29 & 0,0 & 0,0 & 0,0 & 10,7 \\
\hline 30 & 0,4 & 0,0 & 8,4 & 0,0 \\
\hline 31 & 0,0 & & 31,6 & 0,9 \\
\hline Total & 101,8 & 183,5 & 229,7 & 283,5 \\
\hline
\end{tabular}

\section{RESULTADOS E DISCUSSÃO}

A cobertura florística apresentava-se com predominância de capim-colchão (Digitaria horizontalis), guanxumapreta (Sida rhombifolia) e guanxuma-branca (Sida cordifolia), ocorrendo também em menor intensidade ervaquente (Spermacoce latifolia) e picão-preto (Bidens pilosa).

Verificou-se que as diferentes combinações de glyphosate+carfentrazone-ethyl $(360+30,720+25$ e $1080+20$ $\mathrm{g} / \mathrm{ha}$ ) proporcionaram excelente controle do picão-preto, guanxuma-preta e da guanxuma-branca, obtendo-se aos 28 DAT, controle total das três espécies infestantes, equivalendo-se à mistura padrão utilizada (glyphosate+2,4-D a $720+$ 670 e $1080+402 \mathrm{~g} / \mathrm{ha}$ ) (Tabelas 2 e 3 ).

Constatou-se ainda, que a mistura em tanque glyphosate+carfentrazone-ethyl proporcionou excelente controle destas três espécies, mesmo quando se utilizaram doses reduzidas do glyphosate.

Os herbicidas glyphosate e 2,4-D, aplicados isoladamente, também propiciaram bom controle das duas espécies de guanxuma e do picão-preto, apesar de haver ocorrido rebrota de algumas plantas das guanxumas.

Algumas espécies, tais como as guanxumas, destacamse pela importância ou competividade no sistema de plantio direto. A guanxuma-preta ( $S$. rhombifolia) pode perenizarse (Skora Neto, 1998), o que poderá afetar a dessecação da mesma.

As guanxumas apresentavam de 20 a $80 \mathrm{~cm}$ de altura, sendo algumas já perenizadas; mesmo assim, foi possível obter controle total das mesmas aos 28 DAT, o que evidencia a boa ação herbicida da mistura em tanque de glyphosate+carfentrazone-ethyl.

Por outro lado, Marochi (1996), em ensaio conduzido em Ponta Grossa-PR, utilizando herbicidas dessecantes, conseguiu eficaz controle de Bidens pilosa, com o emprego de glyphosate $(2,0 \mathrm{l} / \mathrm{ha})$ e glyphosate $+2,4-\mathrm{D}(2,0+1,0 \mathrm{l} / \mathrm{ha})$, confirmando os resultados obtidos neste ensaio.

A erva-quente foi controlada eficazmente pela combinação glyphosate+carfentrazone-ethyl $(720+25$ e $1080+20 \mathrm{~g} /$ ha), obtendo respectivamente, aos 28 DAT, 95 e $96 \%$ de controle, apesar de não proporcionarem controle total desta espécie. Contudo, tais resultados foram considerados aceitáveis (Tabela 3 ).

Nos outros tratamentos químicos, os níveis de controle obtidos foram inferiores, permitindo a rebrota da erva-quente.

A erva-quente presente nas parcelas experimentais, encontrava-se com 8 a $15 \mathrm{~cm}$ de altura e em pleno vigor vegetativo no momento da aplicação dos herbicidas (período com muita chuva). Estes aspectos possivelmente contribuíram para o bom controle da mistura glyphosate+carfentrazone-ethyl sobre esta e demais espécies, sendo aconselhável, nesta situação, a sua utilização.

Quanto ao capim-colchão, observou-se que a utilização de glyphosate (720 e $1080 \mathrm{~g} / \mathrm{ha})$ e das combinações de 
Tabela 2. Percentagem de controle (dessecação), aos 8, 18 e 28 dias após os tratamentos (DAT), de Digitaria horizontalis, Sida rhombifolia e $S$. cordifolia em plantio direto de soja. Chapadão do Céu, GO. 1999.

\begin{tabular}{|c|c|c|c|c|c|c|c|c|c|c|}
\hline \multirow{4}{*}{ Tratamento } & \multirow{4}{*}{$\begin{array}{c}\text { Dose } \\
(\mathrm{g} / \mathrm{h} \mathbf{a})\end{array}$} & \multicolumn{9}{|c|}{ Controle $(\%)$} \\
\hline & & \multicolumn{3}{|c|}{ D. horizontalis } & \multicolumn{3}{|c|}{ S. rhombifolia } & \multicolumn{3}{|c|}{ S. cordifolia } \\
\hline & & \multicolumn{9}{|c|}{ DAT } \\
\hline & & 8 & 18 & 28 & 8 & 18 & 28 & 8 & 18 & 28 \\
\hline Glyphosate & 720 & 96 & 100 & 100 & 84 & 86 & 90 & 86 & 94 & 95 \\
\hline Glyphosate & 1080 & 98 & 100 & 100 & 86 & 90 & 95 & 90 & 96 & 98 \\
\hline Glyphosate $+2,4-D$ & $720+670$ & 98 & 100 & 100 & 95 & 98 & 100 & 90 & 96 & 95 \\
\hline Glyphosate $+2,4-D$ & $1080+402$ & 99 & 100 & 100 & 95 & 100 & 100 & 93 & 98 & 99 \\
\hline Glyphosate + carfentazone-ethyl & $360+30$ & 96 & 100 & 100 & 80 & 98 & 100 & 90 & 96 & 100 \\
\hline Glyphosate+carfentazone-ethyl & $720+25$ & 98 & 100 & 100 & 90 & 100 & 100 & 95 & 100 & 100 \\
\hline Glyphosate + carfentazone-ethyl & $1080+20$ & 99 & 100 & 100 & 93 & 100 & 100 & 96 & 100 & 100 \\
\hline $2,4-\mathrm{D}$ & 670 & 30 & 40 & 50 & 60 & 95 & 96 & 60 & 95 & 96 \\
\hline Testem unha & - & 0 & 0 & 0 & 0 & 0 & 0 & 0 & 0 & 0 \\
\hline
\end{tabular}

Tabela 3. Percentagem de controle (dessecação), aos 8,18 e 28 dias após os tratamentos (DAT), de Spermacoce latifolia e Bidens pilosa em plantio direto de soja. Chapadão do Céu, GO. 1999.

\begin{tabular}{|c|c|c|c|c|c|c|c|}
\hline \multirow{4}{*}{ Tratam ento } & \multirow{4}{*}{$\begin{array}{c}\text { Dose } \\
(\mathrm{g} / \mathrm{h} \mathrm{a})\end{array}$} & \multicolumn{6}{|c|}{ Controle $(\%)$} \\
\hline & & \multicolumn{3}{|c|}{ S. latifolia } & \multicolumn{3}{|c|}{ B.pilosa } \\
\hline & & \multicolumn{6}{|c|}{ D A T } \\
\hline & & 8 & 18 & 28 & 8 & 18 & 28 \\
\hline G lyphosate & 720 & 60 & 70 & 65 & 88 & 100 & 100 \\
\hline Glyphosate & 1080 & 75 & 83 & 82 & 92 & 100 & 100 \\
\hline G lyphosate $+2,4-D$ & $720+670$ & 82 & 90 & 88 & 92 & 100 & 100 \\
\hline G lyphosate $+2,4-D$ & $1080+402$ & 83 & 92 & 89 & 94 & 100 & 100 \\
\hline G lyphosate+carfentazone-ethyl & $360+30$ & 81 & 88 & 87 & 88 & 100 & 100 \\
\hline G lyphosate+carfentazone-ethyl & $720+25$ & 86 & 94 & 94 & 92 & 100 & 100 \\
\hline Glyphosate+carfentazone-ethyl & $1080+20$ & 87 & 96 & 96 & 94 & 100 & 100 \\
\hline $2,4-\mathrm{D}$ & 670 & 80 & 86 & 84 & 94 & 100 & 100 \\
\hline Testem un ha & - & 0 & 0 & 0 & 0 & 0 & 0 \\
\hline
\end{tabular}

glyphosate $+2,4-\mathrm{D}(720+670$ e $1080+402 \mathrm{~g} / \mathrm{ha})$ e glyphosate + carfentrazone-ethyl $(360+30,720+25$ e $1080+20 \mathrm{~g} / \mathrm{ha})$, proporcionaram controle total desta gramínea, aos 28 DAT (Tabela 2), o que demonstra a acentuada sensibilidade desta espécie infestante. Marochi (1996), também observou que a aplicação de glyphosate $(2,0 \mathrm{l} / \mathrm{ha})$ e de glyphosate+2,4-D $(2,0+1,0 \mathrm{l} / \mathrm{ha})$, sobre o capim-colchão, propiciaram eficiente controle desta gramínea, em ensaio conduzido em Ponta Grossa-PR.

O bom desempenho dos produtos foi, em parte, devido a sua aplicação quando as plantas daninhas apresentavam-se em intenso desenvolvimento vegetativo e sob condições ambientais favoráveis, principalmente em termos de precipitação.

O pousio invernal tem sido uma prática utilizada no ecossistema cerrado para a implantação de culturas no sistema de plantio direto, em áreas já bastante infestadas por gramíneas e espécies dicotiledôneas. A grande vantagem deste sistema tem sido a não necessidade da implantação de uma espécie para formação de cobertura morta. Entretanto, este sitema apresenta o inconveniente de aumentar a densidade das plantas daninhas na área, devido à intensa produção de sementes pelas infestantes, elevando o banco de sementes no solo (Skora Neto, 1998).

Analisando o controle geral (dessecação) da comunidade infestante, verificou-se que a mistura glyphosate+carfentrazone-ethyl $(720+25$ e $1080+20 \mathrm{~g} / \mathrm{ha})$, proporcionou eficiente controle das plantas daninhas infestantes estudadas, equivalendo à combinação glyphosate+2,4-D (720+670 e 1080+402 g/ha). Portanto, é possível a substituição de 2,4-D pelo carfentrazone-ethyl, nas misturas com o glyphosate, para dessecação das plantas daninhas avaliadas, em especial as guanxumas e a erva-quente.

Entretanto, a combinação glyphosate+carfentrazoneethyl $(360+30 \mathrm{~g} / \mathrm{ha})$, apresentou um nível menor de controle da erva-quente. Como nas áreas a serem dessecadas existe um complexo de espécies infestantes, torna-se necessária a utilização de doses mais elevadas de glyphosate (mínimo de $720 \mathrm{~g} / \mathrm{ha}$ ) na constituição da mistura. 


\section{CONCLUSÕES}

A combinação glyphosate+carfentrazone-ethyl $(720+25$ e $1080+20 \mathrm{~g} / \mathrm{ha})$, proporcionou eficiente controle do capim-colchão, picão-preto, guanxuma-branca, guanxumapreta e erva-quente, equivalente ao padrão glyphosate $+2,4$ D $(720+670$ e $1080+402 \mathrm{~g} / \mathrm{ha})$.

A mistura glyphosate + carfentrazone-ethyl $(360+30$ $\mathrm{g} / \mathrm{ha}$ ) também proporcionou controle eficaz das plantas invasoras, exceto para erva-quente, na qual o controle foi considerado satisfatório, aceitável para a infestação da área.

O glyphosate ( 720 e $1080 \mathrm{~g} / \mathrm{ha}$ ) proporcionou eficiente controle do capim-colchão, picão-preto, e das guanxumas e deficiente controle da erva-quente.

O herbicida 2,4-D (670 g/ha), controlou eficazmente as guanxumas e o picão-preto mas apresentou controle deficiente da erva-quente e do capim-colchão.

É possivel substituir o herbicida 2,4-D pelo carfentrazone-ethyl, nas misturas com glyphosate (dose mínima de $720 \mathrm{~g} / \mathrm{ha}$ ), para a dessecação das plantas daninhas estudadas.

\section{LITERATURA CITADA}

EMBRAPA. Centro Nacional de Pesquisa de Soja (Londrina, PR). Recomendações técnicas para cultura da soja na Região Central do Brasil - 1996/1997. Londrina: Embrapa-CNPS, 1997. Cap. 9, p. 85-103.
FERREIRA, F.; CARVALHO, J. A.; BRITO, C.H. Mistura de flumioxazin mais glyphosate em sistema de dessecação de Sida glaziovii e Euphorbia heterophylla em plantio direto. In: XI REPEC, Resultados de pesquisas. Ilha Solteira, SP: Embrapa e FEIS/UNESP, 1998. p. 113-118.

FMC. Carfentrazone-ethyl, produto em fase experimental. Campinas, SP, s.d., n.p.

MAROCHI, A. I. Avaliação de métodos de controle químico para Richardia brasiliensis (poaia-branca), infestando área sob plantio direto da região Sul do Brasil. ZAPP: O desafio do novo. São Paulo, SP: ZENECA Agrícola, 1996. p. $175-186$

MELHORANÇA, A. L.; JÚNIOR, J. A. de S. Efeito de flumioxazin aplicado isolado e em mistura com glyphosate na dessecação para plantio de soja. In: XI REPEC, Resultados de pesquisas. Ilha Solteira, SP: Embrapa e FEIS/ UNESP, 1998. p. 37-41.

PEREIRA, F. de A. R.; FUKUSHIMA, E. H. Avaliação do herbicida flumioxazin em mistura com glyphosate, visando a dessecação de plantas daninhas de soja. In: XI REPEC, Resultados de pesquisas. Ilha Solteira, SP: Embrapa e FEIS/UNESP, 1998. p. 20-24.

SKORA NETO, F. Manejo de plantas daninhas. In: Plantio direto, pequena propriedade sustentável. Londrina, PR: IAPAR, 1998. p. 128-158 (IAPAR. Circular, 101). 
Revista Brasileira de Herbicidas, v.2, n.1, 2001. 